In der Rubrik "Literatur kompakt" werden die wichtigsten Originalarbeiten aus der internationalen Fachliteratur referiert.

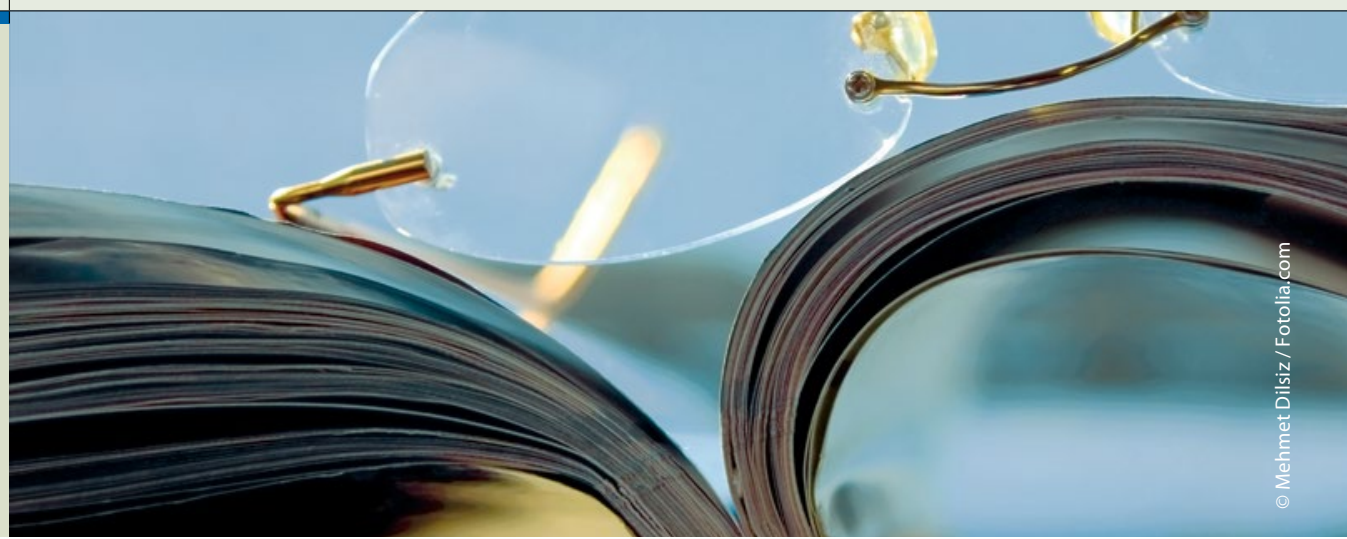

\section{Neuer Ansatz gegen Akne}

\section{Ein topischer Hemmstoff der Sebumproduktion hat sich in einer Phase-Ila-Studie bei Acne vulgaris im Gesicht bewährt.}

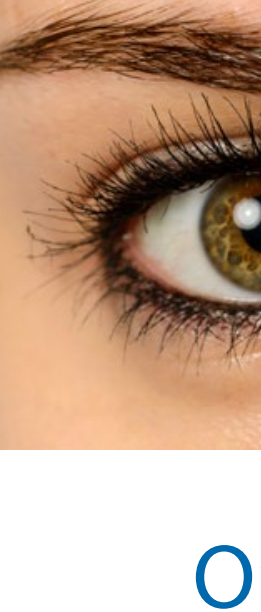
lumacostat-Glasaretil (OG) ist ein Prodrug, die aktive Form blockiert den ersten, geschwindigkeitslimitierenden Schritt in der De-novo-Synthese von Fettsäuren: Durch kompetitive Inhibition des Enzyms Acetyl-CoenzymA(CoA)Carboxylase wird die Umwandlung von Acetyl-CoA in Malonyl-CoA verhindert. In kultivierten menschlichen Sebozyten bewirkt OG, dass die Mehrzahl der im Sebum enthaltenen Fettsäurekomponenten nicht mehr produziert wird; im Tiermodell reduziert der Wirkstoff die zwölf Wochen schnitt die OG-Gruppe in allen Wirksamkeitsendpunkten signifikant besser ab als die Kontrollgruppe: Die Zahl der entzündlichen Läsionen war um 19,3 gesunken, ein Rückgang um 63,9\%; in der Kontrollgruppe waren es 13,3 Läsionen weniger, eine Reduktion um $45,9 \%$. Die nicht entzündlichen Läsionen waren um 19,9 versus 11,2 zurückgegangen ( $48,1 \%$ vs. $28,8 \%)$. Eine Verbesserung des Akneschweregrades um mindestens zwei Stufen auf der fünfstufigen Investigator Global Assessment (IGA) Scale (0-4; $0=$ klares Hautbild, 4 $=$ schwere Akne) erreichten $24,5 \%$ der OG- und 7,3\% der Kontrollpatienten.

Unter OG wurden häufiger Nebenwirkungen an den Applikationsstellen beobachtet, meist waren sie leicht bis moderat. Bei zwei OG-Patienten führten Erytheme, Trockenheit und Schmerz zum Studienabbruch. Von den Vergleichspatienten beendete einer die Behandlung, weil sich die Akne verschlechtert hatte.

Fazit: Die Monotherapie mit topischem OG ist nach dieser Phase-IIa-Studie eine wirksame und gut verträgliche Therapie bei Acne vulgaris im Gesicht. Nach Einschätzung der Studienautoren lässt sich die Wirksamkeit mit der von Kombinationspräparaten etwa aus Clindamycin und Benzoylperoxid vergleichen. In größeren Studien sollen nun die Ergebnisse überprüft und die Dosierung von OG optimiert werden. Dr. Beate Schumacher

Bissonnette $\mathrm{R}$ et al. Olumacostat glasaretil, a novel topical sebum inhibitor, in the treatment of acne vulgaris: A phase Ila, multicenter, randomized, vehicle-controlled study. J Am Acad Dermatol 2017; 76: 33-9 